\title{
Larvicidal activity of granulated pharmaceutical products using Indonesian holy basil leaf extract
}

Azis Ikhsanudin, Lolita Lolita, Zayyana Septya Ramadani

Faculty of Pharmacy, Universitas Ahmad Dahlan, Yogyakarta, Indonesia

\begin{tabular}{l} 
Article Info \\
\hline Article history: \\
Received Apr 27, 2021 \\
Revised Aug 12, 2021 \\
Accepted Aug 26, 2021 \\
\hline
\end{tabular}

Keywords:

Aedes aegypti

Granules

Larvicide

Ocimum sanctum Linn

\begin{abstract}
Ocimum sanctum Linn, known as holy basil, is a larvicide, which is relatively safe compared to synthetic insecticides. This study investigates the larvicidal activity of a granule formulation of Indonesian holy basil leaf extract against third larval instar of Aedes aegypti. The extract of holy basil leaves was obtained by a maceration process with $96 \%$ ethanol. The granule was formulated with various concentrations of holy basil leaf extract, including F1 (2000 ppm), F2 (4000 ppm), and F3 (6000 ppm). The extract contained terpenoid, alkaloid, saponin, flavonoid, and polyphenol compounds. The extract granules had a moisture content of $3.01 \%$, flowability of 1.51 seconds, and dispersion time of 1.09 seconds. The mortality rates of mosquitos treated with the different formulation groups were significantly different from positive control with values of $25.33 \%$ (F1), $50.67 \%(\mathrm{~F} 2)$, and $90.67 \%$ (F3). In conclusion, the granulated formulation of holy basil leaf extract has a larvicidal $\mathrm{LC}_{50}$ of $4405.803 \mathrm{ppm}$ and $\mathrm{LC}_{90}$ of $6080.714 \mathrm{ppm}$. Therefore, a granulated pharmaceutical product derived from holy basil leaf extract could be developed as a potent larvicide to control dengue fever.
\end{abstract}

This is an open access article under the CC BY-SA license.

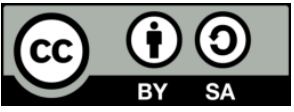

\section{Corresponding Author:}

Azis Ikhsanudin

Faculty of Pharmacy

Universitas Ahmad Dahlan

Jl. Prof. Dr. Soepomo, SH, Janturan Umbulharjo, Yogyakarta, Indonesia

Email: azis.ikhsanudin@pharm.uad.ac.id

\section{INTRODUCTION}

Dengue fever, a viral infection, has been rapidly spread by the Aedes aegypti mosquito and has infected 2.5 billion people worldwide. The WHO reports that there are currently 50 million cases of dengue fever annually. The tropical climate in Indonesia is a significant factor in the reproduction of the mosquito vectors of dengue virus (DENV) such as Aedes aegypti and Aedes albopictus. In most regions of Indonesia, DENV is endemic with a mortality rate of $1 \%$ [1], [2].

Vaccinations and antivirals can be used as strategic therapeutic management tools to control dengue fever. However, these strategic developments are still under appraisal and are yet to be applied in large human populations. Mosquito vector control is an important alternative for reducing dengue fever incidence. The control of mosquito vectors is carried out to terminate the chain of infection by eradicating mosquito larvae and thereby reducing the incidence of mosquito bites [3], [4]. Use of synthetic larvicides may lead to vector resistance and environmental damage [5]. Furthermore, the use of organophosphate larvicides may induce various diseases in humans, such as cardiovascular disease, male impotence, nervous system disorders, dementia, non-Hodgkin lymphoma, disorders of pregnancy duration, and neurological problem in children [6]. Hence, natural and environmentally safe vector control products are urgently required [7]. 
An Indonesian plant that could potentially be developed as a larvicide is the holy basil plant. Holy basil leaf contains several chemical compounds that are toxic for mosquito larvae, such as flavonoids, saponins, tannins, and eugenols [8], [9]. Previous study stated that the ethanolic extract of holy basil leaf has larvicidal activity against the third larval instar of Aedes aegypti with an $\mathrm{LC}_{50}$ value of $1290.39 \mathrm{ppm}$ and an $\mathrm{LC}_{90}$ value of $3173.53 \mathrm{ppm}$ [10], [11]. In this study, the larvicidal activity was performed on the crude extract of holy basil leaf. To the best of our knowledge, no larvicidal pharmaceutical products have been developing from holy basil leaf. Therefore, we formulated a granule product of holy basil extract and evaluated its larvicidal activity against the third larval instar of Aedes aegypti. Granulation improves the surface texture, porosity, wettability in order to increase disintegration and solubility of active substances [12]. Furthermore, the granulation process can produce large particles from the active substance that may increase the flowability and accuracy of dosage [13], [14]. Overall, this study aims to develop holy basil leaf into a potent and easy-to-use larvicide with high activity.

\section{RESEARCH METHOD}

\subsection{Materials}

Holy basil leaves (Ocimum sanctum Linn) were collected from Kulonprogo District, Special District of Yogyakarta Province, Indonesia. The plant sample was identified in the Laboratory of Plant Taxonomy, Department of Biology, Faculty of Mathematics and Natural Sciences, Universitas Ahmad Dahlan. Aedes aegypti at the third larval instar were provided by the Laboratory of Entomology, Faculty of Public Health, Universitas Ahmad Dahlan. The granule was composed of lactose, amylum manihot, magnesium stearate, polyvinylpyrrolidone (PVP) which were obtained from Brataco, Indonesia. Temephos was obtained from BASF, Indonesia. All ingredients were of standard analytical grade.

\subsection{Methods}

\subsubsection{Preparation of extract}

Samples of holy basil were dried in a shady place. The dried holy basil leaf was ground into a soft powder. The powder was dried once more in a shady place at room temperature $\left(27-30^{\circ} \mathrm{C}\right)$ in the afternoon. $650 \mathrm{~g}$ of dried holy basil leaf powder was processed by maceration in proper ethanol solvent. Furthermore, it was poured into a $500 \mathrm{~mL}$ glass beaker and mixed for 180 minutes per days at $200 \mathrm{rpm}$. The mixing process was done at a temperature of around $25-28^{\circ} \mathrm{C}$. Finally, the solvent was evaporated using a rotary evaporator (IKA RV $8 \mathrm{~V}$ ) to obtain the dense mass extract.

\subsubsection{Organoleptic evaluation of extract}

Organoleptic evaluation of the extract was performed by observing colour, odour, taste, and consistency. The evaluation of extract consistency was done using a density parameter by pressing the extracted sample between the thumb and the index finger, and assigning a subjective density score.

\subsubsection{Identification of chemical compound of extract}

Screening of chemical compounds present in the extract of Ocimum sanctum Linn was done to determine the plant's active substances. We evaluated the presence of ethanols, terpenoids, alkaloids, saponins, flavonoids, and polyphenols [15], [16]. The holy basil leaf extract was poured into a test tube for each experiment. Classes of chemical compounds were identified as follows:

a) Identification of ethanols

$5 \mathrm{ml}$ extract was added by $1 \mathrm{ml} \mathrm{NaOH} 1 \mathrm{~N}$ slowly. After three minutes, added $0.1 \mathrm{ml}$ of PVP. If the extract contains ethanol, thus iodoform odour will spread, and yellow sediments will be visible within 30 minutes [17].

b) Identification of terpenoids

Two drops of holy basil extract were placed into the test tube, which have been added 2-3 drops of acetic anhydride solution. Furthermore, it was stirred slowly until dry while being added 1-2 drops of concentrated sulphuric acid. Terpenoid was identified if the green or a bluish colour visible in the test tube [16].

c) Identification of alkaloids

$0.5 \mathrm{~g}$ of the extract was poured into a test tube and added $2 \mathrm{ml}$ of ethanol $96 \%$ while being stirred. The next stage was adding HCL $2 \mathrm{~N}$ and heating on a water bath. After the mixture cooled, then it was filtered and added some drops of Mayer's reagent. The sample was observed until sedimentation being formed [18].

d) Identification of saponins

$0.2 \mathrm{~g}$ of the extract was dissolved into $5 \mathrm{ml}$ of distilled water and was heated it until boiling. After cooling, the solution was filtered and $3 \mathrm{ml}$ of distilled water was added to the filtrate while shaking. Saponins could be identified in the extract if a stable foam was formed [19]. 
e) Identification of polyphenols

$200 \mathrm{mg}$ of basil leaf extract was dissolved in $10 \mathrm{ml}$ of solvent for 20 minutes in a water bath. Furthermore, the filtrate was cooled and three drops of $\mathrm{FeCl}_{3}$ were added. Polyphenols were indicated by a colour change to bluish-green [20].

\subsubsection{Granulated formulation from holy basil extract}

In our study, the treatment groups were allocated based on the different concentrations of the holy basil leaf extract by 2000 ppm (F1), 4000 ppm (F2), and 6000 ppm (F3). The negative control group used a placebo without holy basil extract. A positive control group contains active substances of temephos. The additional ingredients needed for formulating the granules consist of filler and binder. Lactose was used as the filler, whereas amylum, magnesium stearate, and PVP were the binder. The composition of granules forming consists of 50\% active substances and 50\% excipients, as shown in Table 1.

Table 1. The formula of holy basil extracts granules

\begin{tabular}{lcccc}
\hline \multicolumn{1}{c}{ Ingredients } & Placebo & F1 & F2 & F3 \\
\hline Extract ethanol of holy basil leaf (ppm) & 0 & 2000 & 4000 & 6000 \\
Lactose (\%) & 45 & 45 & 45 & 45 \\
Amylum (\%) & 3 & 3 & 3 & 3 \\
Magnesium stearate (\%) & 1 & 1 & 1 & 1 \\
PVP (\%) & 1 & 1 & 1 & 1 \\
\hline
\end{tabular}

\subsubsection{Physical characteristics test of holy basil leaf extract granules}

Moisture content evaluation was performed by applying the Moisture Balance Toledo. $1000 \mathrm{mg}$ granules of holy basil leaf ethanolic extract were placed into the apparatus with a temperature set at $105^{\circ} \mathrm{C}$ for 15 minutes. A good percentage of moisture granules is 3-5\% [21]. As much as $25 \mathrm{~g}$ granules were placed into a funnel with a valve at the bottom of the apparatus. The bottom valve was opened; thus, the granules could flow down to be contained in a glass beaker. Flow time test was done by recording the time needed for the granule to flow [22]. $400 \mathrm{mg}$ of granules were poured into a glass, thus approximately adding $1000 \mathrm{~mL}$ of water. The time needed for the granule to be dispersed entirely was recorded. A good dispersion time of granules was less than five minutes [23].

\subsubsection{Larvicidal activity test}

The larval instar of Aedes aegypti was placed into a tray filled with distilled water up to $100 \mathrm{ml}$. Furthermore, several amount granules of holy basil leaf ethanol extract were added based on each concentration needed. Positive control was used temephos with a concentration of $0.01 \%$. Replication was done as much as three times for each treatment group. The observation was done after 24 hours by analyzing the percentage of larva mortality rate [24].

\subsection{Data analysis}

Data were analyzed by applying the ANOVA method with a 95\% significance level. Moreover, all statistical analyses were performed to determine the value of the least significant difference (LSD) posthoc test by using software SPSS version 22 (IBM Corp., Armonk, NY., USA). The larva mortality rate was also analyzed with a probit model to determine the $\mathrm{LC}_{50}$ and $\mathrm{LC}_{90}$ values.

\section{RESULTS AND DISCUSSION}

We have succeeded in formulating granules from the ethanol extract of holy basil leaf into various formulas. Our study showed that the granule of holy basil leaf had a good appearance. The larvicide activity of holy basil leaf granules could be seen in the $\mathrm{LC}_{50}$ dan $\mathrm{LC}_{90}$ score. The detailed findings related to the physical characteristics and larvicide activity could be described in the explanation below.

\subsection{Organoleptic result of holy basil leaf ethanol extract}

The holy basil leaf extract was observed visually in its organoleptic characteristics such as colour, odour, taste, and consistency. The organoleptic test of holy basil leaf extract was deep brownish-green colour, holy basil specific odour, bitter taste, dense and sticky consistency, as seen in Table 2 . The chemical substances in the holy basil leaf extract are terpenoids, alkaloids, saponins, flavonoids dan polyphenols, as seen in Table 2. A previous study demonstrated that alkaloid and terpenoid substances could act as larvicide [25]. 
Table 2. The chemical substances and organoleptic parameters of holy basil leaf extract

\begin{tabular}{ccccc}
\hline Chemical substance & Description & Result & \multicolumn{2}{c}{ Organoleptic parameter } \\
\hline Terpenoids & Dark green colour & + & Colour & Deep brownish green \\
Alkaloids & White sedimentation & + & Odour & Holy basil leaf \\
Saponins & Permanent sedimentation & + & Taste & Bitter \\
Flavonoids & Intensive yellow colour & + & Consistency & Dense, sticky \\
Polyphenols & Green-blue colour & + & & \\
\hline Note: $(+)$ existence & & & &
\end{tabular}

Table 2 reports that holy basil leaf extract consists of terpenoids, proven by the colour change into dark green. This change was caused by adding a concentrated sulphuric acid to the sample [26]. The extract also consists of alkaloid substances which formed the white sedimentation due to nitrogen reaction in alkaloids with the metal ion $\mathrm{K}^{+}$of potassium tetraiodomercurate (II) to produce potassium-alkaloid complex [27]. The saponins in the extract were signified by forming stable foam caused by the glycoside [28]. Saponins, a glycoside, had a steroidal aglycone and triterpenoid, in which the glycosyl group was bound to atom $C_{3}$ [29]. The extract also consists of flavonoids proven by the colour change on the filter paper from pale yellow into intensive yellow after being vaporized with ammonia. This colour change was caused by ammonia, causing the hydroxyl group to be ionized and changing the length of wave absorption. Polyphenols in the extract were also identified by the extracted colour changing into the dark green after adding $\mathrm{FeCl}_{3}$. This mechanism was caused by the interaction between the $\mathrm{Fe}^{3+}$ hydroxyl group in the polyphenol [30].

\subsection{Physical characteristics test of granule holy basil leaf extract}

The granule extract of holy basil leaf was evaluated for its specific physical characteristics such as moisture content, flow time, and dispersion time. The physical characteristic of granulated formulation holy basil extract was round and homogenous. Furthermore, the granule colour becomes darker with the increase of extract concentration in the granules. Moisture content had a significant impact on granule flowability. The higher moisture content could result in a decrease in the granule flowability. Furthermore, it could influence the lower quality of granules due to the most significant growth of microbes and fungi. The moisture content results are shown in Table 3.

Table 3. Moisture content test result

\begin{tabular}{cccccc}
\multicolumn{5}{c}{ Parameter } & \multicolumn{4}{c}{ Means \pm SD $(\%)$} \\
& Placebo & F1 & F2 & F3 & p-value \\
\hline Moisture content & $3.09 \pm 0.01$ & $3.09 \pm 0.01$ & $3.10 \pm 0.01$ & $3.10 \pm 0.04$ & 0.245 \\
\hline
\end{tabular}

Table 3 reports that the percentage of average moisture content (MC \%) in each group as follows:

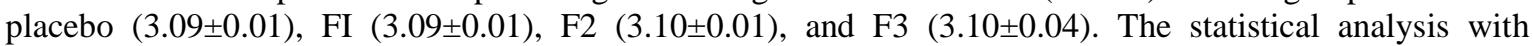
ANOVA shows no significant difference in the moisture content percentage between formulas $(\mathrm{p}>0.05)$. The granulation process aimed to form a strong bond between particles of the granule to maintain product handling. The primary mechanism of binding formation between granule particles was caused by the cohesion and adhesion force on the surface of the liquid film. These attractive forces could build a solid bridge interlocking due to the water content in the pores of the granule particle [31]. A good humidity should create a thin layer of adsorption film by reducing the distance between particles. Hence, a wider contact region between particulates could produce a strong particle bond. The moisture content of the granule strongly influenced the process of the bonding mechanism. The good moisture content of granules ranged from $2-5 \%$ [32]. In this study, the moisture content test of granule had met the standard requirements.

Flow time was a vital parameter requirement of the granules, affecting the volume uniformity in the filling and packaging. A reasonable flow time requirement was less than 10 seconds for $100 \mathrm{~g}$ granule or 2.5 seconds for $25 \mathrm{~g}$ granule [33]. The flow time test of the holy basil leaf extract granule could be seen in Table 4 .

Table 4. The flow time test and LSD posthoc test result

\begin{tabular}{cccccc}
\hline \multirow{2}{*}{ Formula } & \multirow{2}{*}{ Means \pm SD (second) } & \multicolumn{4}{c}{ p-value } \\
& & Placebo & F1 & F2 & F3 \\
\hline Placebo & $0.50 \pm 0.01$ & - & $0.000^{*}$ & $0.000^{*}$ & $0.000^{*}$ \\
F1 & $1.43 \pm 0.02$ & $0.000^{*}$ & - & $0.000^{*}$ & $0.000^{*}$ \\
F2 & $1.53 \pm 0.02$ & $0.000^{*}$ & $0.000^{*}$ & - & $0.000^{*}$ \\
F3 & $1.57 \pm 0.02$ & $0.000^{*}$ & $0.000^{*}$ & $0.030^{*}$ & - \\
\hline Note: ${ }^{*}$ p-value less than 0.05 & & & &
\end{tabular}


Table 4 indicates that F3 has a longer flow time compared to F1, F2, and placebo. This result concluded that more extract concentration in the granule would result in a longer flow time [34]. Magnesium stearate was used as a lubricant in the granule formulation process. This lubricant characteristic had cohesive properties and could increase the flow time by preventing dust powder during the filling process. LSD posthoc test shows a significant difference in flow time in each group of formulas $(p<0.05)$. Each physical characteristic of the extract influenced the difference in granule flow time. A dense characteristic of the extract will impact the particle interaction's granule flow forming a liquid bridge. Furthermore, the nucleation of granules could be created as the small wet particle of extract agglomeration to forms a pendular bridge. This pendular bridge will impact the granule's mass, density, porosity, shape, and fragility. Hence, the granule should be spherical (round), uniform, and firm to reduce the friction force between particles to increase the granule's flow time. The dispersion time will influence the amount of chemical compound in the solvent of extract. Shorter dispersion time might result in more active substances in the extract, affecting larvicide activity. The dispersion time test of granules was shown in Table 5.

Table 5. Dispersion time test and LSD posthoc test result

\begin{tabular}{cccccc}
\hline \multirow{2}{*}{ Parameter } & & \multicolumn{2}{c}{ Means \pm SD $(\%)$} & \multicolumn{2}{c}{ p-value } \\
& Negative control & F1 & F2 & F3 & \\
\hline Dispersion percentage & $1.17 \pm 0.06$ & $1.13 \pm 0.06$ & $1.07 \pm 0.06$ & $1.07 \pm 0.12$ & 0.344 \\
\hline
\end{tabular}

Table 5 reports that the increased concentration of holy basil leaf extract in the granule will result in a faster dispersion time. The statistic test result with LSD posthoc indicates no significant differences in dispersion time between each formula $(\mathrm{p}>0.05)$. The result concludes that the concentration of holy basil leaf extract does not influence the dispersion time of granules. The disintegrant ability in developing the disintegration force was based on the active ingredients. The granule swelling process was more effective in using ingredients that are not easily dissolved in water. Porosity will increase swiftly in a hydrophilic matrix. The dissolution and disintegration force will decrease due to the disintegrant particle space expands without disturbing the matrix. In this study, we used amylum as the disintegrant. As a disintegrant, amylum could form a hydrogen bond in the granulation to enhance the swelling process. Amylum might also facilitate the liquid transporting into the granule pores to increase the absorption of a liquid substance entering the granule pores. In our study, each formula consisted of an equal amount of amylum which caused the dispersion time to have statistically significant differences.

\subsection{Larvicidal activity of holy basil leaf ethanol extract granule}

The larvicidal activity test of granulated formulation of holy basil leaf ethanol extract was based on the standard of WHO by using the third larval instar of Aedes aegypti. The larvicidal activity assessed the value of $\mathrm{LC}_{50}$ dan $\mathrm{LC}_{90}$. The mortality rate of Aedes aegypti was observed 24 hours towards various formulas of granules holy basil leaf ethanol extract. The percentage of larva mortality rate could be seen in Table 6 .

Table 6. The percentage of larva mortality rate

\begin{tabular}{ccccccc}
\hline \multirow{2}{*}{ Formula } & \multirow{2}{*}{ Means \pm SD $(\%)$} & Negative control & P-value (LSD posthoc test) & \\
& & Positive control & F1 & F2 & F3 \\
\hline Negative control & $0 \pm 0$ & - & $0.025^{*}$ & $0.034^{*}$ & $0.037^{*}$ & $0.034^{*}$ \\
Positive control & $100 \pm 0$ & $0.025^{*}$ & - & $0.034^{*}$ & $0.037^{*}$ & $0.030^{*}$ \\
F1 & $25.33 \pm 0.57$ & $0.034^{*}$ & $0.034^{*}$ & - & $0.046^{*}$ & $0.043^{*}$ \\
F2 & $50.67 \pm 1.53$ & $0.037^{*}$ & $0.037^{*}$ & $0.046^{*}$ & - & $0.046^{*}$ \\
F3 & $90.67 \pm 0.57$ & $0.034^{*}$ & $0.030^{*}$ & $0.043^{*}$ & $0.046^{*}$ & - \\
\hline
\end{tabular}

Table 6 concludes that the holy basil leaf extract granules had a potent larvicidal activity. This study suggested that a higher concentration of holy basil leaf extract will increase larvicidal activity. Table 6 also reports that the negative control does not have larvicidal activity. Gokulakrishnan et al. suggested that the extract of methanol, ethyl acetate, and hexane of Ocimum sanctum Linn had larvicide activity towards the larva Culex quinquefasciatus [35]. The $\mathrm{LC}_{50}$ and $\mathrm{LC}_{90}$ probability scores were counted based on the larva mortality rate percentage. The probability score of $\mathrm{LC}_{50}$ and $\mathrm{LC}_{90}$ could be seen in Table 7 . 
Table 7. Probability score of $\mathrm{LC}_{50}$ dan $\mathrm{LC}_{90}$

\begin{tabular}{ccc}
\hline Probability & Estimation of concentration $(\mathrm{ppm})$ & Concentration $(\%)$ \\
\hline 0.100 & 3192.240 & 0.319 \\
0.250 & 3718.597 & 0.372 \\
0.500 & 4405.803 & 0.441 \\
0.750 & 5220.006 & 0.522 \\
0.900 & 6080.714 & 0.608 \\
0.990 & 7907.394 & 0.791 \\
\hline
\end{tabular}

Table 7 explains the probability value of larva mortality by $\mathrm{LC}_{50}$ of $4405.803 \mathrm{ppm} \sim(0.44 \%)$ and $\mathrm{LC}_{90}$ of $6080.714 \mathrm{ppm} \sim(0.608 \%)$. This percentage of larva mortality was caused by the active substances in the holy basil leaf extract. Moreover, Figure 1 shows that the larvicide activity will increase by adding holy basil leaf extract concentration in the granules.

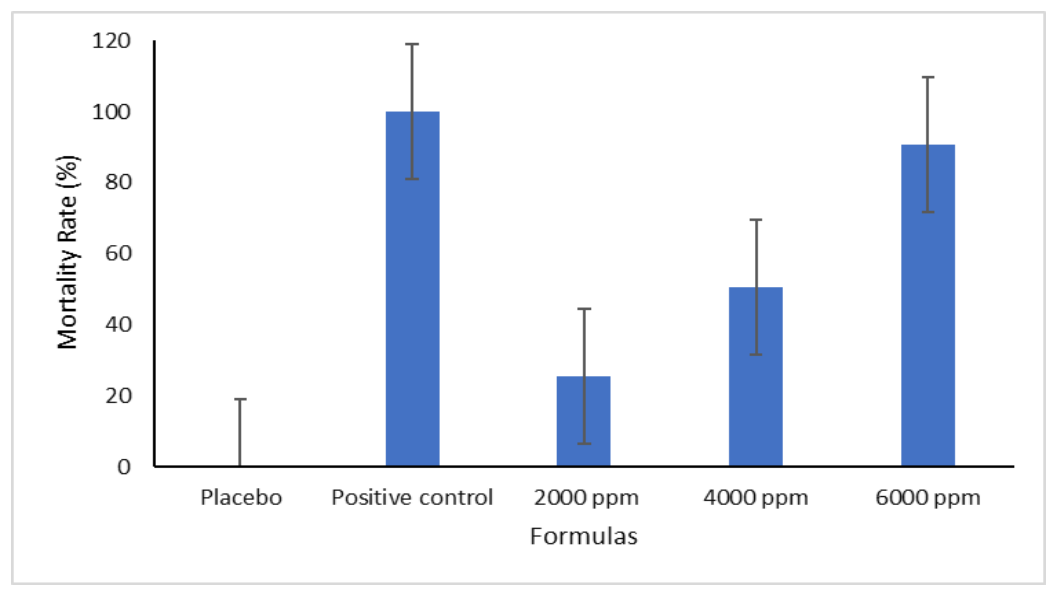

Figure 1. The mortality rate of third larval instar of Aedes aegypti

Regarding the 24 hours observation towards the third larval instar of Aedes aegypti, it concludes that F3 (6000 ppm) had the highest activity of larvicide with a value of $90.67 \%$, continued by the F2 (4000 ppm) by $50.67 \%$ and F3 (2000 ppm) by $25.33 \%$. Table 6 shows a significant difference in the larvicidal activity in each formula $(\mathrm{p}<0.05)$. F3 has a higher activity of larvicidal compared to the other formulas. The larvicidal activity of holy basil leaf extract granules was influenced by several active substances such as terpenoids, alkaloids, saponins, and flavonoids dan polyphenols. The mechanism of alkaloids as larvicide was caused by acetylcholinesterase (AChE) inhibition responsible for nerve impulse transmission across a synapse. The terpenoids group could facilitate the transmission into the membrane resulting in paralysis and death to the larva. The mechanism of saponins as larvicide was not clearly understood yet. In addition, the central hypothesis of saponin might act as a repellant and toxic towards cells. The saponin's properties inside water and organic solvent will damage the larva's cuticular membrane [36]. Flavonoids have been reported as a larvicide by hindering acetylcholinesterase enzyme in the mosquito larvae to terminate the food supply and the larva growth [10]. The role of phenolic groups as larvicide has also been suggested that phenolic fraction may influence mosquito growth by reducing adult larva fertility, fecundity, and lifespan [37]. This mechanism was followed by decreasing carbohydrate and fat content in the early stage of larvae instar Aedes aegypti. The synergy of whole secondary metabolites in the holy basil leaf ethanolic extract will result in the potent larvicidal activity of granulated pharmaceutical formulation.

\section{CONCLUSION}

Holy basil leaf ethanolic extract granule (Ocimum sanctum Linn) consists of terpenoids, alkaloids, flavonoids, saponins dan polyphenols with a larvicidal activity value of $\mathrm{LC}_{50} 4405.803 \mathrm{ppm}$ and $\mathrm{LC}_{90}$ $6080.714 \mathrm{ppm}$. Therefore, the granulated formulation of holy basil leaf extract could be further developed as a novel larvicide for managing the mosquito vector. 


\section{REFERENCES}

[1] E. P. Astuti, P. W. Dhewantara, H. Prasetyowati, M. Ipa, C. Herawati, and K. Hendrayana, "Paediatric dengue infection in Cirebon, Indonesia: a temporal and spatial analysis of notified dengue incidence to inform surveillance," Parasit. Vectors, vol. 12, no. 1, pp. 1-12, 2019, doi: 10.1186/s13071-019-3446-3.

[2] B. Haryanto, "Indonesia Dengue Fever: Status, Vulnerability, and Challenges," Curr. Top. Trop. Emerg. Dis. Travel Med., 2018, doi: 10.5772/intechopen.82290.

[3] D. Raj Mohan and M. Ramaswamy, "Evaluation of larvicidal activity of the leaf extract of a weed plant, Ageratina adenophora, against two important species of mosquitoes, Aedes aegypti and Culex quinquefasciatus," African J. Biotechnol., vol. 6, no. 5, pp. 631-638, 2007, doi: 10.5897/AJB2007.000-2060.

[4] H. Perumalsamy, M. J. Jang, J. R. Kim, M. Kadarkarai, and Y. J. Ahn, "Larvicidal activity and possible mode of action of four flavonoids and two fatty acids identified in Millettia pinnata seed toward three mosquito species," Parasites and Vectors, vol. 8, no. 1, pp. 1-14, 2015, doi: 10.1186/s13071-015-0848-8.

[5] E. P. Lima et al., "Insecticide resistance in Aedes aegypti populations from Cearáe, Brazil," Parasites and Vectors, vol. 4, no. 1, pp. 1-12, 2011, doi: 10.1186/1756-3305-4-5.

[6] P. Nicolopoulou-Stamati, S. Maipas, C. Kotampasi, P. Stamatis, and L. Hens, "Chemical Pesticides and Human Health: The Urgent Need for a New Concept in Agriculture,” Front. Public Heal., vol. 4, no. July, pp. 1-8, 2016, doi: 10.3389/fpubh.2016.00148.

[7] A. Rajasekaran and G. Duraikannan, "Larvicidal activity of plant extracts on Aedes Aegypti L," Asian Pac. J. Trop. Biomed., vol. 2, no. 3 SUPPL, pp. S1578-S1582, 2012, doi: 10.1016/S2221-1691(12)60456-0.

[8] N. E. Firmansyah, A. Aulung, H. Wibowo, and R. Subahar, "Activity of Ocimum sanctum Leaf Extract against Aedes aegypti Larvae: Midgut Histopathological Alteration,” ASPIRATOR - J. Vector-borne Dis. Stud., vol. 11, no. 1, pp. 13-18, 2019, doi: 10.22435/asp.v11i1.215.

[9] T. Varun, Y. Ruchi, S. A. Kumar, T. Vivek, Y. Shweta, and V. Veer, "Larvicidal activity of leaf extract of some weeds against malaria vector Anopheles stephensi," International Journal of Malaria Research and Reviews, vol. 1, no. 3, pp. 35-39, 2013.

[10] A. C. J. De Souza Wuillda, R. C. C. Martins, and F. D. N. Costa, "Larvicidal activity of secondary plant metabolites in aedes aegypti control: An overview of the previous 6 years," Nat. Prod. Commun., vol. 14, no. 7, pp. 1-11, 2019, doi: 10.1177/1934578X19862893.

[11] D. Baranitharan, "Mosquito Larvicidal Properties of Ocimum sanctum Linn. (Lamiaceae) AGAINST Aedes aegypti (Linn.), Anopheles stephensi (Liston), Culex quinquefasciatus (Say)," Life Sci. Arch., vol. 1, pp. 46-52, Feb. 2015.

[12] J. Wang, H. Wen, and D. Desai, "Lubrication in tablet formulations," Eur. J. Pharm. Biopharm., vol. 75, no. 1, pp. 1-15, 2010, doi: 10.1016/j.ejpb.2010.01.007.

[13] M. R. M. Usman, A. S. Mahajan, and S. R. Pawar, "Effect of Size Reduction and Drying Technology on Granules Production,” World J. Pharm. Pharm. Sci., no. August, pp. 1653-1664, 2017, doi: 10.20959/wjpps20177-9610.

[14] M. Szumilo, P. Belniak, K. Swiader, E. Holody, and E. Poleszak, "Assessment of physical properties of granules with paracetamol and caffeine," Saudi Pharm. J., vol. 25, no. 6, pp. 900-905, 2017, doi: 10.1016/j.jsps.2017.02.009.

[15] L. Mousavi, R. M. Salleh, and V. Murugaiyah, "Phytochemical and bioactive compounds identification of Ocimum tenuiflorum leaves of methanol extract and its fraction with an antidiabetic potential," Int. J. Food Prop., vol. 21, no. 1, pp. 2390-2399, 2018, doi: 10.1080/10942912.2018.1508161.

[16] J. B. Harborne and C. A. Williams, "Advances in flavonoid research since 1992," Phytochemistry, vol. 55, no. 6, pp. 481-504, 2000, doi: 10.1016/S0031-9422(00)00235-1.

[17] G. Karthivashan, M. Tangestani Fard, P. Arulselvan, F. Abas, and S. Fakurazi, "Identification of bioactive candidate compounds responsible for oxidative challenge from hydro-ethanolic extract of Moringa oleifera leaves," J. Food Sci., vol. 78, no. 9, pp. C1368-75, Sep. 2013, doi: 10.1111/1750-3841.12233.

[18] M. Masturah, K. H. Dewi, N. Jalil, L. W. Jia, S. R. Sheikh Abdullah, and I. Mushrifah, "Phytochemical screening and alkaloid identification of Cabomba furcata," in Advanced Materials Research, vol. 233, pp. 971-976, 2011, doi: 10.4028/www.scientific.net/AMR.233-235.971.

[19] A. S. Ashour, M. M. A. El Aziz, and A. S. Gomha Melad, "A review on saponins from medicinal plants: chemistry, isolation, and determination," J. Nanomedicine Res., vol. 7, no. 4, pp. 282-288, 2019, doi: 10.15406/jnmr.2019.07.00199.

[20] R. Hosseinzadeh, K. Khorsandi, and S. Hemmaty, "Study of the effect of surfactants on extraction and determination of polyphenolic compounds and antioxidant capacity of fruits extracts," PLoS One, vol. 8, no. 3, pp. 1-7, 2013, doi: 10.1371/journal.pone.0057353.

[21] P. Thapa, A. R. Lee, D. H. Choi, and S. H. Jeong, "Effects of moisture content and compression pressure of various deforming granules on the physical properties of tablets," Powder Technol., vol. 310, pp. 92-102, 2017, doi: 10.1016/j.powtec.2017.01.021.

[22] J. I. N. Baosheng, T. A. O. He, and W. Zhong, "Flow behaviors of non-spherical granules in rectangular hopper," Chinese J. Chem. Eng., vol. 18, no. 6, pp. 931-939, 2010, doi: 10.1016/S1004-9541(09)60150-6.

[23] N. Tanaka et al., "Development of novel sustained-release system, disintegration-controlled matrix tablet (DCMT) with solid dispersion granules of nilvadipine," J. Control. release, vol. 108, no. 2-3, pp. 386-395, 2005, doi: 10.1016/j.jconrel.2005.08.024

[24] M. Larvicides, "Guidelines for laboratory and field testing of mosquito larvicides," World Heal. Organ., pp. 1-41, 2005, [Online]. Available: http://whqlibdoc.who.int/hq/2005/WHO_CDS_WHOPES_GCDPP_2005.13.pdf. 
[25] R. S. Rattan, "Mechanism of action of insecticidal secondary metabolites of plant origin," Crop Prot., vol. 29, no. 9, pp. 913-920, 2010, doi: 10.1016/j.cropro.2010.05.008.

[26] M. Ioelovich, "Study of Cellulose Interaction with Concentrated Solutions of Sulfuric Acid," ISRN Chem. Eng., vol. 2012, pp. 1-7, 2012, doi: 10.5402/2012/428974.

[27] A. Hassan, P. Achakzai, and H. Nangyal, "Detection and Estimation of Alkaloids, Saponins and Tannins in Herbs of Quetta Baluchistan," American-Eurasian J. Agric. \& Environ. Sci., vol. 15, no. 6, pp. 985-990, 2015, doi: 10.5829/idosi.aejaes.2015.15.6.94130.

[28] A. W. Wanyama, "Evaluation of Phytoconstituents, Antioxidants Potential, Cytotoxic, Antimicrobial Activities and Mineral Composition of Vigna subterranea (L) Verdic. Extracts." JKUAT-COHES, 2018, [Online], Available: http://hdl.handle.net/123456789/4557.

[29] J.-P. Vincken, L. Heng, A. de Groot, and H. Gruppen, "Saponins, classification and occurrence in the plant kingdom," Phytochemistry, vol. 68, no. 3, pp. 275-297, Feb. 2007, doi: 10.1016/j.phytochem.2006.10.008.

[30] Y. Suresh, G. Rajasekar, T. Lavanya, B. Lakshminarsimhulu, K. S. Reddy, and S. R. Reddy, "Antioxidant and antidiabetic properties of isolated fractions from methanolic extract derived from the whole plant of Cleome viscosa L.," Futur. J. Pharm. Sci., vol. 6, no. 1, pp. 1-18, 2020, doi: 10.1186/s43094-020-00122-1.

[31] H. E. M. A. Mahmoud, N. H. H. Bashir, and Y. O. H. Assad, "Effect of basil (Ocimum basilicum) Leaves Powder and Ethanolic-Extract on the 3rd Larval Instar of Anopheles arabiensis (Patton, 1905) (Culicidae: Diptera)," Int. J. Mosq. Res., vol. 4, no. 2, pp. 52-56, 2017.

[32] L. Jing, C. Y. Kwok, Y. F. Leung, and Y. D. Sobral, "Extended CFD-DEM for free-surface flow with multi-size granules," Int. J. Numer. Anal. Methods Geomech., vol. 40, no. 1, pp. 62-79, 2016, doi: 10.1002/nag.2387.

[33] J. P. Lakshman, J. Kowalski, M. Vasanthavada, W. Tong, Y. M. Joshi, and A. T. M. Serajuddin, "Application of melt granulation technology to enhance tabletting properties of poorly compactible high-dose drugs," J. Pharm. Sci., vol. 100, no. 4, pp. 1553-1565, 2011, doi: 10.1002/jps.22369.

[34] G. Morin and L. Briens, "The effect of lubricants on powder flowability for pharmaceutical application," AAPS PharmSciTech, vol. 14, no. 3, pp. 1158-1168, Sep. 2013, doi: 10.1208/s12249-013-0007-5.

[35] J. Deepa, J. Gokulakrishnan, M. Baranitharan, and S. Dhanasekaran, "Larvicidal activity of Indian medicinal plants on the Dengue fever mosquito Aeges aegypti Linnaeus," Int. J. Pure Appl. Zool., vol. 3, no. 2, pp. 130-136, 2015.

[36] P. M. Gutierrez, A. N. Antepuesto, B. A. L. Eugenio, and M. F. L. Santos, "Larvicidal activity of selected plant extracts against the dengue vector Aedes aegypti mosquito," Int. Res. J. Biol. Sci., vol. 3, no. 4, pp. 23-32, 2014.

[37] U. Devi and D. Bora, "Growth inhibitory effect of phenolic extracts of Ziziphus jujuba Mill. in dengue vector Aedes aegypti (L) in parent and F1 generation," Asian Pac. J. Trop. Med., vol. 10, no. 8, pp. 787-791, Aug. 2017, doi: 10.1016/j.apjtm.2017.08.003. 